\section{How to shorten a plant breeding program? A case study with ornamental peppers}

\section{Priscila Alves Barroso ${ }^{1^{*}}$, Mailson Monteiro do Rêgo ${ }^{2}$, Joelson Germano Crispim $^{3}$, Maria do Perpétuo Socorro Damasceno Costa $^{2}$ and Elizanilda Ramalho do Rêgo ${ }^{2}$}

\begin{abstract}
Plant breeding of ornamental peppers (Capsicum spp.) can be supported by biotechnological tools. The objective of this study was to evaluate the efficiency of an in vitro culture of immature zygotic embryos (IZE) to reduce the breeding cycle of ornamental pepper (C. annuum) in comparison to the conventional system. Three ornamental pepper genotypes were used: UFPB 001, UFPB 004, and UFPB 099. Embryos at 30 days after selfing were inoculated in MS $1 / 2$-strength culture medium, and at the same time, seeds were placed to germinate in a commercial substrate. Approximately 215 days are required from selfing until fruit ripening in the conventional system, whereas the IZE system requires an average of 153 days, a decrease of approximately 30\% per selection cycle, corresponding to 496 days considering 8 selfing cycles. A decrease in time, labor, and inputs makes the IZE system a suitable tool for shortening the breeding program of ornamentals peppers.
\end{abstract}

Keywords: Capsicum annuum L., biotechnology, embryos, breeding of ornamentals.

\section{INTRODUCTION}

Pepper (Capsicum spp.) is one of the most important vegetables cultivated in the world and the variation in color, fruit shape, and leaf shape has drawn attention to them as ornamental plants (Bosland and Votava 2000, Rêgo et al. 2009, Rêgo and Rêgo 2016, Rêgo and Rêgo 2018). The ornamental breeding program involves several selfing cycles, usually seven cycles, whether by the mass selection process in landraces or breeding through hybridization and conducting segregating populations to obtain pure lines (Seguí-Simarro 2010, Rêgo et al. 2015, Rêgo and Rêgo 2016, Rêgo and Rêgo 2018).

The breeding cycle of Capsicum is relatively long compared to other Solanaceae species such as tomato and eggplant (Manzur et al. 2013). The length of the cycle depends on the genotype and local climate conditions (Bosland and Votava 2000, Manzur et al. 2014). Thus, techniques that can reduce the length of the breeding cycle will have two advantages: shortening the breeding program up to release of a new cultivar and reduction in costs (Manzur et al. 2014, Gatti et al. 2016).

One of the best-known techniques for reducing the breeding cycle is production of doubled haploids (DH). Compared to conventional methods,
Crop Breeding and Applied Biotechnology 19: 193-199, 2019 Brazilian Society of Plant Breeding. Printed in Brazil http://dx.doi.org/10.1590/198470332019v19n2a27

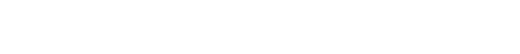




\section{PA Barroso et al.}

the DH technique has the advantage of reduction in the time and costs necessary for acquisition of homozygote lines, reducing the number of generations of selfings and obtaining all loci in homozygosis (Seguí-Simarro 2010). Despite all its advantages, the DH technique is far from being used in most species as a laboratory routine (Salas et al. 2012, RivasSendra et al. 2017). The regeneration of DH in pepper from microspores and anthers has been reported (Kim et al. 2008, Ari et al. 2011, Popova et al. 2016), but they are known as recalcitrant for androgenesis and regeneration of haploid embryos, requiring the identification of responsive genotypes (Irikova et al. 2011). The development and germination of haploid embryos has been reported as the main drawback for the efficient production of doubled-haploid peppers (Segui Simarro 2016); the presence of embryos with some deformity is common, or the embryos are induced, but with no further embryonic development (Barany et al. 2005, Supena et al. 2006, Kim et al. 2008).

The production of seedlings from immature zygotic embryos (IZE), may be an alternative to reduce the breeding cycle in recalcitrant species such as pepper plants. The breeding cycle for peppers starts from selfing or crossing until obtaining seeds in the fruit (Manzur et al. 2014). For breeding of ornamental peppers, fully ripe fruit is necessary; the germination percentage when the fruit is harvested unripe is low or zero (Sánchez et al. 1993). When interspecific Capsicum hybrids are used, this fact can be intensified, since they naturally have low germination (Martins et al. 2015). In vitro cultivation of immature zygotic embryos (IZE) can reduce the breeding cycle, considering that it is not necessary to wait for seed maturation in the fruit (Gatti et al. 2016). This biotechnological technique can be used in combination with conventional methods such as single seed descent (SSD), which allows homozygous lines and/or recombinant inbred lines (RIL) to be obtained in a relatively short time (Bermejo et al. 2016).

Manzur et al. (2013) and Manzur et al. (2014), working with five genotypes of pepper in the climate conditions of the Mediterranean coast of Spain, reduced the reproductive cycle from 148-184 days in the conventional method to 93-133 days, depending on the genotype, through embryo culture. These authors considered the anthesis of the first three flowers from the zygotic embryo plants as the end of the breeding cycle, a stage in which the breeder can perform new selfings. This criterion can be used when the technique is combined with the SSD method, for example. In ornamental pepper breeding programs in which the Pedigree method is used, selection in segregating populations is mainly performed based on quantitative and qualitative traits of the fruit (Rêgo et al. 2011, Rêgo and Rêgo 2016, 2018). Given the importance of these traits in the ornamental pepper ideotype, it is necessary to extend the breeding cycle until 3 pieces of fruit have matured.

The objective of this study was to evaluate the efficiency of the in vitro culture of immature zygotic embryos (IZE system) in order to shorten the length of the breeding cycle of ornamental pepper genotypes (C. annuum L.) in comparison to the conventional system.

\section{MATERIAL AND METHODS}

\section{Plant material and growing conditions}

The experiment was carried out in the Laboratório de Biotecnologia e Melhoramento Vegetal at the Centro de Ciências Agrárias (CCA), Universidade Federal da Paraíba (UFPB), Areia, PB, Brazil. Three ornamental pepper genotypes were used: UFPB 001, UFPB 004, and UFPB 099, obtained from the Capsicum Germplasm Bank at the Laboratório de Biotecnologia e Melhoramento Vegetal (CCA/UFPB). These accessions were previously tested for ornamental potential through diallel analysis (Pessoa et al. 2017).

Thirty seeds of each genotype were sown in 200-cell polystyrene seedling trays filled with Basaplant substrate. The seedlings were transplanted to $900-\mathrm{mL}$ pots containing the above-mentioned substrate at the 6-leaf stage and kept in a greenhouse until the flowering stage, at which time selfings were performed to determine the cycle in the conventional and IZE systems.

\section{Conventional system}

Flowers close to the pre-anthesis stage (balloon stage) were selected for selfings using the method proposed by Rêgo et al. (2012). The selfed flowers were marked and identified with the date on which the selfings were performed. When the fruit was ripe, the seeds were removed and after 24 hours sown in polystyrene trays and transplanted into pots as previously described. They remained in the greenhouse until ripening of the new fruit. 


\section{IZE system}

The selfed flowers (Rêgo et al. 2012) for the IZE system were tagged and identified with the date on which the selfings were performed. Fruit was collected thirty days after selfings (DAS).

Under a dissecting microscope, the embryos were isolated and inoculated in Petri dishes $(60 \times 15 \mathrm{~mm})$ with $1 / 2$ of the nutrient concentration of the Murashige and Skoog (1962) medium plus $40 \mathrm{~g} \mathrm{~L}^{-1}$ of sucrose $+8 \mathrm{~g} \mathrm{~L}^{-1}$ of agar +0.01 $\mathrm{mg} \mathrm{L}^{-1}$ of indole-3-acetic acid (IAA), and $0.01 \mathrm{mg} \mathrm{L}^{-1}$ of gibberellic acid ( $\left.\mathrm{GA}_{3}\right)$; $\mathrm{pH}$ was adjusted to 5.7 (Manzur et al. 2013). The medium was pre-autoclaved at $121{ }^{\circ} \mathrm{C}$ for 15 minutes, and the growth regulators were filter-sterilized and added to the medium after autoclaving. The Petri dishes were maintained in a growth room at a controlled temperature of 24 \pm 1 으 under fluorescent light in a 16-h photoperiod.

When the seedlings reached the Petri dish lid, they were transferred to glass vials containing $30 \mu \mathrm{l}$ of MS medium $(1 / 2)$ for a period of 7 days for acclimatization. The seedlings were removed from the glass vials, washed with distilled, deionized, and autoclaved water (DDA) to remove the excess of culture medium, and transferred to plastic cups containing $50 \mathrm{~mL}$ of DDA water. The containers were covered with plastic bags $(10 \times 15 \mathrm{~cm})$ fixed with a rubber band and kept in the laboratory at $26 \pm 1{ }^{\circ} \mathrm{C}$. After $24 \mathrm{~h}$, the water was withdrawn and the containers filled with commercial Basaplant ${ }^{\circ}$ substrate, and once more covered with a plastic bag. After $48 \mathrm{~h}$, the plastic bags were removed and the seedlings remained in the laboratory. When the seedlings reached the 4-leaf stage, they were transferred to plastic pots containing $900 \mathrm{~mL}$ of commercial substrate. The pots were kept in a shaded environment for 3 days and then transferred to a greenhouse until ripening of the new fruit.

\section{Breeding cycle determination}

The breeding cycle was divided into the following phases according to the method adapted from Manzur et al. (2014): i) phase 1: from selfings to obtaining seeds (conventional method) or, alternatively, to embryo isolation and culture (IZE system), ii) phase 2: from seed sowing or embryo culture until transplanting, iii) phase 3 , from transplanting until the beginning of anthesis (anthesis of the first three flowers), and iv) phase 4, from anthesis of the first three flowers until ripening of the first three pieces of fruit.

\section{Statistical analysis}

To determine the breeding cycle, 10 plants of each genotype were evaluated. A completely randomized experimental design was used. Analysis of variance and comparison of means by the Tukey test for the genotypes were performed separately for the conventional and IZE systems. The $t$ test $(p \leq 0.05)$ was used to compare the contrast of means between the conventional and IZE systems for each development phase. The R 3.4.1 software (R CORE TEAM 2017) was used.

\section{RESULTS}

\section{Conventional system}

Statistical differences were observed among genotypes by the conventional system only in phase I, corresponding to the period from selfings to obtaining seeds (Table 1 ). Sixty-nine days were required until fruit ripening and obtaining seeds in genotype UFPB 004, while genotype UFPB 099 had viable seeds at 63 days, thus characterized as the earliest genotype. Seeds were obtained in the UFPB 001 genotype at 66 days after selfings.

Table 1. Conventional breeding cycle of three ornamental pepper genotypes (Capsicum annuum L.)

\begin{tabular}{|c|c|c|c|c|c|}
\hline Genotype & Phase I & Phase II & Phase III & Phase IV & Total \\
\hline 001 & $65.8 \mathrm{ab} *$ & $47.6 a$ & $49.6 a$ & $51 a$ & $214 a$ \\
\hline 004 & $69.2 a$ & $49.0 a$ & $49.6 a$ & $48.4 a$ & $216.6 a$ \\
\hline 099 & $62.8 \mathrm{~b}$ & $51.8 \mathrm{a}$ & $50.2 a$ & $47 a$ & $211.8 a$ \\
\hline Average & 65.9 & 49.5 & 49.8 & 48.8 & 214.14 \\
\hline
\end{tabular}

Phase $I^{*}$ : from selfings to seed production (conventional method), Phase II: from seed sowing to transplanting, Phase III: from transplanting to beginning of anthesis, Phase IV: from anthesis to ripening of the first three pieces of fruit. *Means followed by the same letter are not significantly different from each other by the Tukey test ( $\mathrm{k} \leq 0.01$ ). 
Table 2. Breeding cycle using the immature zygotic embryo system (IZE) in three ornamental pepper genotypes (Capsicum annuum L.)

\begin{tabular}{|c|c|c|c|c|c|}
\hline Genotype & Phase I* & Phase II & Phase III & Phase IV & Total \\
\hline 001 & 30 & $26.67 a^{*}$ & $44.90 b$ & $47.0 a$ & $148.55 a$ \\
\hline 004 & 30 & $28.00 a$ & $51.35 a$ & $44.67 a$ & $154.01 a$ \\
\hline 099 & 30 & $26.33 a$ & $52.85 a$ & $44.53 a$ & $153.75 a$ \\
\hline Average & 30 & 27.00 & 49.70 & 45.40 & 152.1 \\
\hline
\end{tabular}

Phase I*: from selfings to embryo isolation and culture (IZE system); Phase II: from seed sowing to transplanting; Phase III: from transplanting to beginning of anthesis; Phase IV: from anthesis to ripening of the first three pieces of fruit. *Means followed by the same letter are not significantly different from each other by the Tukey test ( $p \leq 0.01$ ).

Phase II corresponded to a period of 47.6 to 51.8 days and did not show statistical differences among genotypes. Phase III likewise did not show statistical differences in an average of 50 days. Ripening of the first three pieces of fruit, corresponding to phase IV, required an average of 48.8 days after anthesis, and again, no statistical differences were found among the genotypes.

The breeding cycle length from selfings to fruit ripening required 211.8 (UFPB 099) to 216.6 (UFPB 001) days, and there were no statistical differences among the genotypes.

\section{IZE system}

Using the IZE system, significant influence of the genotypes was observed only for phase III (Table 2). The length of Phase I was 30 days for all genotypes. Phase II, from seed sowing to transplanting, required an average of 27 days.

For Phase III, the genotype UFPB 001 was earlier, with a length of 44.83 days, and no significant differences were observed for this phase between the genotypes UFPB 004 (51.33) and UFPB 099 (52.83).

Phase IV, from anthesis to fruit ripening, required an average of 46 days, with no statistical differences among the genotypes. The total cycle for the IZE system was from 148.5 days (UFPB 001) to 154 days (UFPB 004), and did not differ statistically among the genotypes, with an average of 152.05 days.

\section{Conventional System vs IZE System}

The contrast of mean values in the conventional system vs IZE system, regardless of the genotypes, can be observed in Figure 1. Statistical differences were found for Phases I and II. These phases were the ones where the greatest decrease in time occurred in comparison to the conventional method. These decreases consequently reduced the length of the breeding cycle. In Phase I, a difference of approximately 36 days between the methods was observed, whereas for Phase II, this difference was 22 days. Phases III and IV were statistically equal in the two methods.

In the conventional system, the pepper plants required approximately 215 days to complete the total breeding cycle. Using the IZE system, they required an average of 153 days, a difference of 62 days, shortening the breeding cycle by approximately $30 \%$ (Figure 2 ). If the breeding cycle is compared according to the criterion used by Manzur et al. (2014), in which phase III is considered the end of the cycle, 165.2 days would be necessary in the conventional system up to anthesis of the first three flowers. In the IZE system, this period required 106.7 days, an average decrease of 59 days or reduction of $35 \%$.

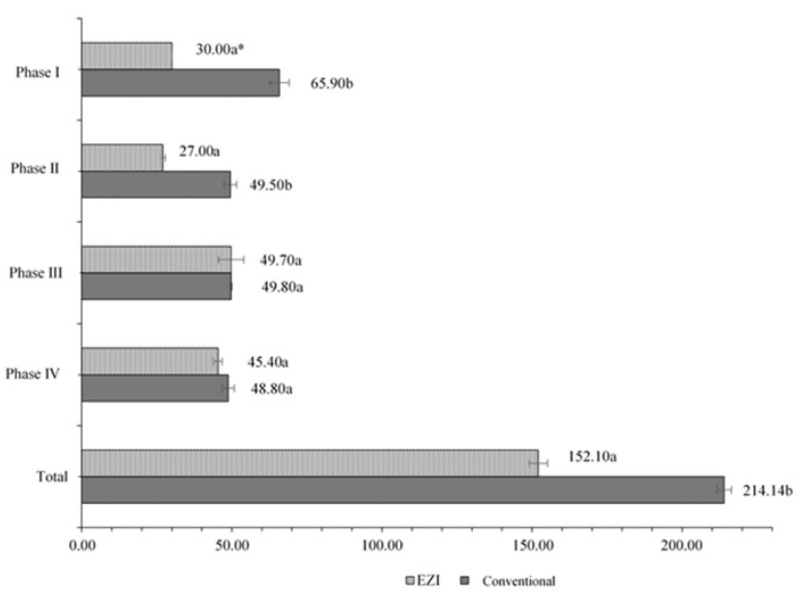

Figure 1. Breeding cycle of ornamental peppers (C. annuum) in the conventional and IZE system. Phase I: From selfings to obtaining seeds (conventional method) and from selfings to obtaining immature zygotic embryos (IZE system), Phase II: from seed sowing to transplanting, Phase III: from transplanting to beginning of anthesis, Phase IV: from anthesis to ripening of the first three pieces of fruit. Means followed by the same letter are not significantly different from each other by the $t$ test $p \leq 0.05$. 


\section{DISCUSSION}

This study demonstrates the efficiency of the in vitro culture technique of immature zygotic embryos (IZE) in shortening the breeding cycle of ornamental peppers. The same technique used to reduce the breeding cycle of sunflower (Dağüstü et al. 2012), wheat (Sharma and Gill 1982), orchid (Yeung et al. 1981), tomato (Gebologlu et al. 2011), pepper and green pepper (Manzur et al. 2014), and lentil (Bermejo et al. 2016) have already been described.

In the conventional system, 212 to 217 days were required from selfings to fruit ripening for the three genotypes used. Immature pepper seeds are successfully recovered at 30 days after selfing and require an average of 153 days for the total cycle (Figure 1). Manzur et al. (2014) determined the conventional breeding cycle in 5 pepper genotypes and found variation from 148 to 184 days, considering anthesis of the first three flowers as the end of the breeding cycle. Through cultivation of embryos, this period was reduced to 93-133 days. The greatest decrease in time was obtained in the green pepper accession, cv. California Wonder; in cultivation of embryos, the period was 60 to 70 days less than the conventional method, corresponding to a reduction of $35-40 \%$. In tomato genotypes, embryo cultivation performed at 20 DAS led to a reduction of 53 to 64 days compared to the conventional method (Gebologlu et al. 2011), results similar to those observed in this study, which confirms that the EZI technique can be successfully applied to Solanaceae. In sunflower, Serieys (1992) reduced the breeding cycle by half through in vitro culture of embryos of 10 days. Also, in sunflower, Dağüstü et al. (2012) observed a variation of 106-160 days in the conventional breeding cycle in 11 genotypes, and this breeding cycle was reduced to 85 95 days, depending on the genotype, through culture of embryos of 12 days after selfing.

Phase I contributed most to reduction in the breeding cycle. The reduction of 10 to 12 days in the time necessary to obtain zygotic embryos observed in sunflower (Dağüstü et al. 2012), for example, would bring an even greater reduction to the breeding cycle of peppers. Yang et al. (2015) emphasizes that reducing the length of the breeding cycle also lowers seed exposure to natural environmental conditions, which reduces the risk of pest and disease damage during maturation of seeds still inside the fruit and in the germination process. Shortening Phase I means even younger embryos are obtained that are very dependent on the endosperm and surrounding maternal tissues. This requires greater in vitro culture medium supplementation (Raghavan 2003). Therefore, new studies should be carried out on pepper plants to enhance the results of the EZI technique in plant breeding.

In autogamous plants, such as peppers, seven to eight generations are necessary to obtain homozygous lines (Seguí-Simarro 2010). In the conventional method, eight generations of selfings using the Pedigree method would require four to five years to obtain pure lines - based on the results obtained in this experiment, 1720 days. With the IZE system, it would be possible to advance eight generations

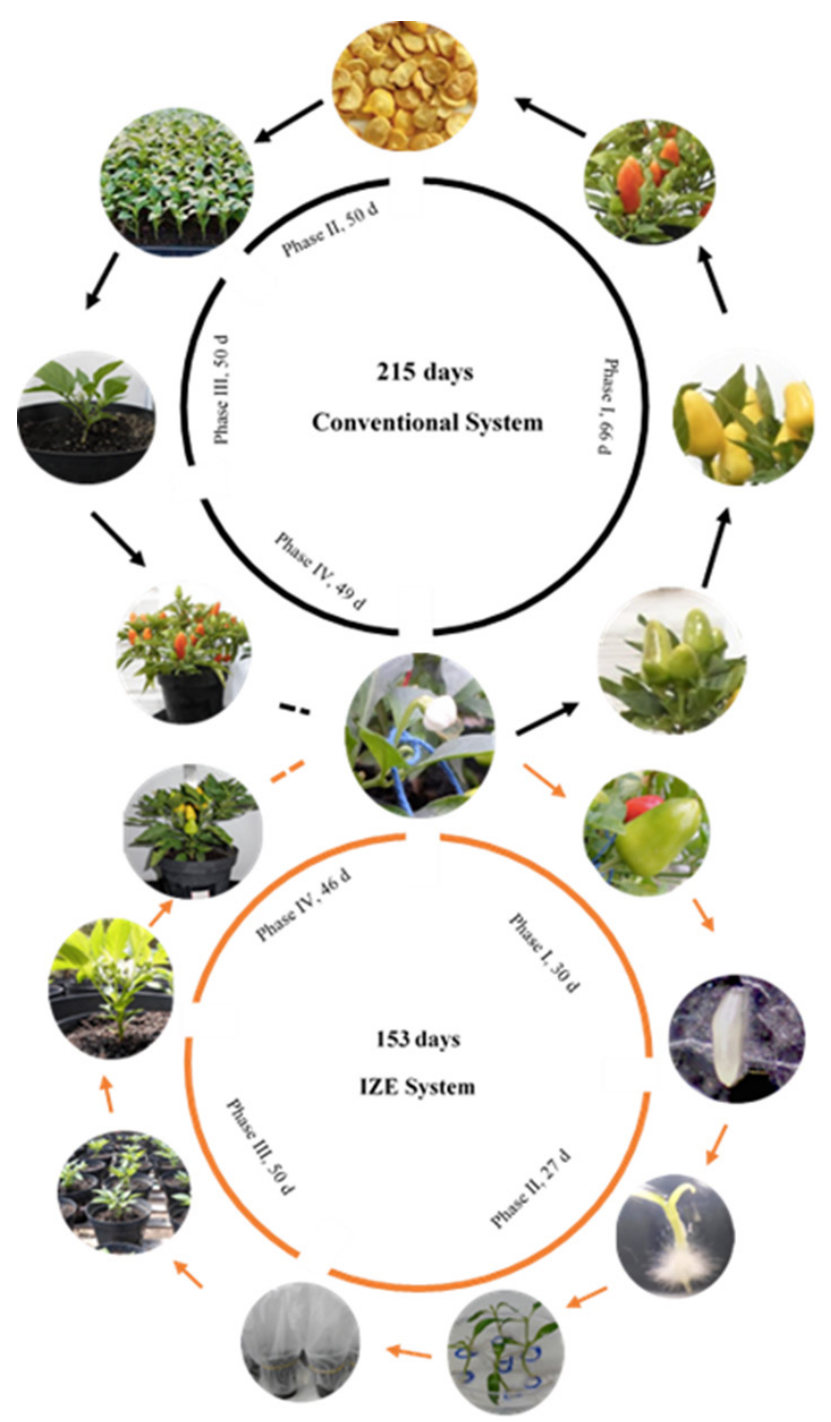

Figure 2. Comparison between two selection cycles in an ornamental pepper breeding program. Conventional system (approximately 215 days) (black arrows) and Immature Zygotic Embryo System (IZE) (approximately 153 days) (orange arrows). Reduction of 62 days per selection cycle (Adapted from Manzur et al. 2014). 


\section{PA Barroso et al.}

in just over three years (1224 days), obtaining homozygous lines faster, reducing costs and labor, and accelerating the development and arrival of the improved variety on the market. Through use of this technique combined with the SSD breeding method, and once more considering phase III as the end of each cycle, three generations of selfed pepper plants could be conducted per year. In lentils, four generations per year could be conducted using embryos excited 18 days after anthesis (Bermejo et al. 2016), demonstrating the viability of this technique.

Genotypic differences for the total number of days required for each cycle were not significant for either system. These results indicate that the methodology can be used for a large number of pepper genotypes that have a phenological cycle similar to the cycles of the genotypes used in this experiment, thus, constituting an efficient tool to shorten ornamental pepper breeding programs.

\section{REFERENCES}

Ari E, Bedir H, Yildirim S, and Yildirim T (2016) Androgenic responses of 64 ornamental pepper (Capsicum annuum L.) genotypes to shedmicrospore culture in the autumn season. Turkish Journal of Biology 40: 706-717.

Barany I, Gonzalez-Melendi P, Fadón B, Mityko J, Risueño MC and Testillano PS (2005) Microspore-derived embryogenesis in pepper (Capsicum annuum L.): subcellular rearrangements through development. Biol Cell 97: 709-722.

Barroso PA, Rêgo MM, Rêgo ER and Soares WS (2015) Embryogenesis in the anthers of different ornamental pepper (Capsicum annuum L.) genotypes. Genetics and Molecular Research 14: 13349-13363.

Bermejo C, Gatti I and Cointry E (2016) In vitro embryo culture to shorten the breeding cycle in lentil (Lens culinaris Medik). Plant Cell, Tissue and Organ Culture 127: 585-590.

Bosland PW and Votava EJ (2000) Peppers: vegetable and spice capsicums. CABI Publishing, New York, 224p.

Dağüstü N, Bayram G, Sincik M and Bayraktaroğlu M (2012) The short breeding cycle protocol effective on diverse genotypes of sunflower (Helianthus annuus L.). Turkish Journal of Field Crops 17: 124-128.

Gatti I, Guindón F, Bermejo C, Espósito A and Cointry E (2016) In vitro tissue culture in breeding programs of leguminous pulses: use and current status. Plant Cell, Tissue and Organ Culture 127: 543-559.

Gebologlu N, Bozmaz S, Aydin MC and Çakmak P (2011) The role of growth regulators, embryo age and genotypes on immature embryo germination and rapid generation advancement in tomato (Lycopersicon esculentum Mill.). African Journal Biotechnology 10: 4895-4900.

Irikova T, Grozeva S, Popov P, Rodeva V and Todorovska E (2011) In vitro response of pepper anther culture (Capsicum annuum L.) depending on genotype, nutrient medium and duration of cultivation. Biotechnology \& Biotechnological Equipment 25: 2604-2609.

Kim M, Jang IC, Kim JA, Park EJ, Yoon M and Lee Y (2008) Embryogenesis and plant regeneration of hot pepper (Capsicum annuum L.) through isolated microspore culture. Plant Cell Reports 27: 425-434.

Manzur JP, Oliva-Alarcón M and Rodríguez-Burruezo A (2014) In vitro germination of immature embryos for accelerating generation advancement in peppers (Capsicum annuum L.). Scientia Horticulturae 170: 203-210.

Manzur JP, Penella C and Rodríguez-Burruezo A (2013) Effect of the genotype, developmental stage and medium composition on the in vitro culture efficiency of immature zygotic embryos from genus Capsicum. Scientia Horticulturae 161: 181-187.

Martins KC, Pereira TNS, Souza SAM, Rodrigues R. and Amaral Junior ATD (2015) Crossability and evaluation of incompatibility barriers in crosses between Capsicum species. Crop Breeding and Applied Biotechnology 15:139-145.

Murashige T and Skoog F (1962) A revised medium for rapid growth and bioassays with tobacco tissue cultures. Physiology Plant 15:473497.

Popova T, Grozeva S, Todorova V, Stankova G, Anachkov N and Rodeva V (2016) Effects of low temperature, genotype and culture media on in vitro androgenic answer of pepper (Capsicum annuum L.). Acta Physiologiae Plantarum 38: 273.

R Core Team (2017) R: A language and environment for statistical computing. Available in < https://www.R-project.org/.> Accessed on May 15, 2018.

Raghavan V (2003) One hundred years of zygotic embryo culture investigations. In Vitro Cellular \& Developmental Biology-Plant 39: 437-442.

Rêgo ER and Rêgo MM (2016) Genetics and breeding of chili pepper Capsicum spp. In Rêgo ER, Rêgo MM and Finger FL (eds) Production and breeding of chilli peppers (Capsicum spp.). Springer International Publishing, Cham, p. 57-80.

Rêgo ER and Rêgo MM (2018) Ornamental pepper. In Van Huylenbroeck $\mathrm{J}$ (ed) Ornamental crops. Springer International Publishing, Cham, p. 529-565.

Rêgo ER, Nascimento MF, Nascimento NFF, Santos RMC, Fortunato FLG and Rêgo MM (2012) Testing methods for producing self-pollinated fruits in ornamental peppers. Horticultura Brasileira 30: 669-672.

Rêgo ER, Rêgo MM and Finger FL (2015) Methodological basis and advances for ornamental pepper breeding program in Brazil. Acta Horticulturae 1087: 309-314

Rêgo ER, Rêgo MM, Cruz CD, Finger FL and Casali VWD (2011) Phenotypic diversity, correlation and importance of variables for fruit quality 
How to shorten a plant breeding program? A case study with ornamental peppers

and yield traits in Brazilian peppers (Capsicum baccatum). Genetic Resources and Crop Evolution 58: 909-918.

Rêgo ER, Rego MM, Finger FL, Cruz CD and Casali VWD (2009) A diallel study of yield components and fruit quality in chilli pepper (Capsicum baccatum). Euphytica 168: 275-287.

Rivas-Sendra A, Campos-Vega M, Calabuig-Serna A and Seguí-Simarro JM (2017) Development and characterization of an eggplant (Solanum melongena) doubled haploid population and a doubled haploid line with high androgenic response. Euphytica 213: 89.

Salas P, Rivas-Sendra A, Prohens J and Seguí-Simarro JM (2012) Influence of the stage for anther excision and heterostyly in embryogenesis induction from eggplant anther cultures. Euphytica 184: 235-250.

Sánchez VM, Sundstrom FJ, McClure GN and Lang NS (1993) Fruit maturity, storage and postharvest maturation treatments affect bell pepper (Capsicum annuum L.) seed quality. Scientia Horticulturae 54: 191-201.

Seguí-Simarro JM (2010) Androgenesis revisited. The Botanical Review 76: 377-404.
Seguí-Simarro JM (2016) Androgenesis in solanaceae. In Germana MA and Lambardi $\mathrm{M}$ (eds) In vitro embryogenesis in higher plants. Humana Press, New York, p. 209-244.

Serieys H (1992) Cytoplasmic effects on some agronomical characters in sunflower. In Proceedings of the $13^{\text {th }}$ international sunflower conference. Pacini, Pisa, p. 1245-1250.

Sharma HC and Gill BS (1982) Effect of embryo age and culture media on plant growth and vernalization response in winter wheat. Euphytica 31: 629-634.

Supena EDJ, Suharsono S, Jacobsen E and Custers JBM (2006) Successful development of a shed-microspore culture protocol for doubled haploid production in Indonesian hot pepper (Capsicum annuum L.). Plant Cell Reports 25: 1-10.

Yang Y, Zhang D, Li Z, Jin X and Dong J (2015) Immature embryo germination and its micropropagation of Ilex crenata Thunb. Hort Science 50: 733-737.

Yeung EC, Thorpe TA and Jensen $\mathrm{Cl}$ (1981) In vitro fertilization and embryo rescue. In Thorpe TA (ed) Plant tissue culture: methods and applications in agriculture. Academic Press, New York, p. 253-271. 